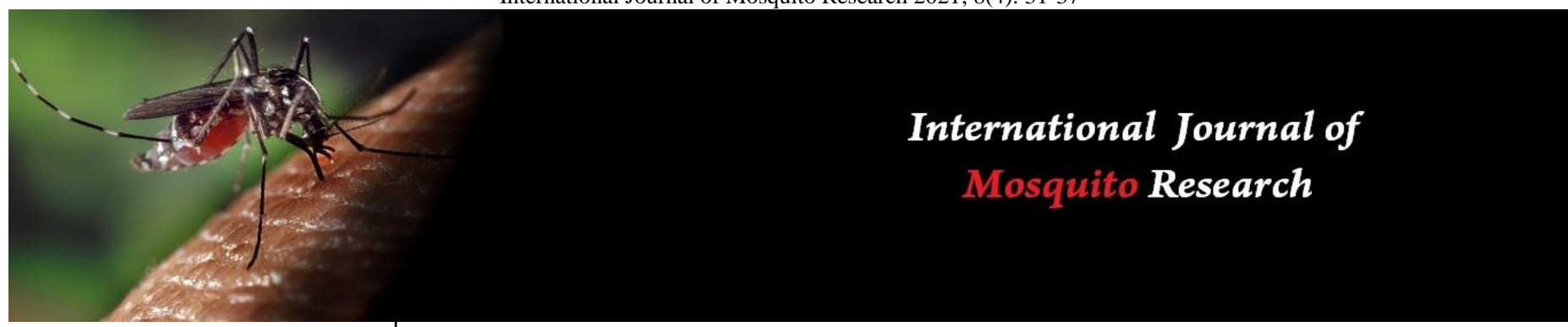

ISSN: 2348-5906

CODEN: IJMRK2

IJMR 2021; 8(4): 31-37

(C) 2021 IJMR

www.dipterajournal.com

Received: 19-05-2021

Accepted: 21-06-2021

NR Padma Priya

Research Scholar, Department of

Zoology and Research Centre,

Scott Christian College

(Autonomous), Nagercoil

Affiliated to Manonmaniam

Sundaranar University,

Abishekapatti, Tirunelveli,

Tamil Nadu, India

RD Stevens Jones

Associate Professor, Department of Zoology and Research Centre,

Scott Christian College

(Autonomous), Nagercoil

Affiliated to Manonmaniam

Sundaranar University,

Abishekapatti, Tirunelveli,

Tamil Nadu, India

Corresponding Author:

NR Padma Priya

Research Scholar, Department of

Zoology and Research Centre,

Scott Christian College

(Autonomous), Nagercoil

Affiliated to Manonmaniam

Sundaranar University,

Abishekapatti, Tirunelveli,

Tamil Nadu, India

\section{Larvicidal activity and GC-MS analysis of Piper longum L. leaf extract fraction against human vector mosquitoes (Diptera: Culicidae)}

\author{
NR Padma Priya and RD Stevens Jones
}

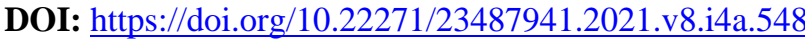

\section{Abstract}

Mosquitoes are the vectors for transmitting major public health diseases like dengue, filariasis, and malaria. Among the various mosquito larval control agents, plant extracts and isolated phytocompounds are good alternatives to control vector mosquitoes. The objective of this study is to test the efficacy of leaf extract fraction prepared from the locally available plant, Piper longum L in decimating the larvae of Aedes aegypti, Anopheles stephensi, and Culex quinquefasciatus. Piper longum leaf extract fraction was isolated through column chromatographic separation and phytochemical analysis was carried out by standard procedures. The larvicidal assay was carried out following WHO methods, and the P. longum fraction was tested at various concentrations $(10-80 \mu \mathrm{g} / \mathrm{dl})$ on the third instar larvae of Ae. aegypti, An. stephensi, and $C x$. quinquefasciatus. The $24 \mathrm{~h} \mathrm{LC}_{50}, \mathrm{LC}_{90}$ values were as determined using probit analysis. GC-MS analysis was done for the identification of bio-active compounds present in the specific $P$. longum leaf fraction. The fraction of $P$. longum leaf extract contains secondary metabolites such as alkaloids, glycosides, saponins, phytosterols, diterpenes, triterpenes, phenols, tannins, steroids, and terpenoids. The $\mathrm{LC}_{50}$ and $\mathrm{LC}_{90}$ values were 38.96 and 41.53; 45.06, and 71.16; 72.02 and $76.80 \mu \mathrm{g} / \mathrm{dl}$ against Ae. Aegypti, An. stephensi, and, Cx. quinquefasciatus respectively. Twenty-nine phytocompounds were identified by GC-MS. The present results suggested that the fraction of P. longum leaf extract checked for mosquito larvicidal activity had an excellent potential for controlling selected human vector mosquitoes.

Keywords: column chromatography, extraction, medicinal plant, phytochemical compounds, soxhlet apparatus

\section{Introduction}

Vector-borne diseases account for more than $17 \%$ of infections, causing more than one million deaths annually ${ }^{[1]}$. Pathogens for diseases such as dengue fever, malaria, Japanese encephalitis, and filariasis are transmitted by the three genera of mosquitoes namely Aedes, Anopheles, and, Culex ${ }^{[2,3]}$. More than 3000 mosquito species belonging to 34 genera in the world, among them only about 300 species are capable of transmitting diseases to humans and other vertebrates ${ }^{[4]}$. Approximately 40 million people in India suffer from mosquito-borne diseases annually and contribute significantly to disease burden, death, poverty, and social debility all over the world, particularly in tropical countries ${ }^{[5]}$. Aedesaegypti is the principal vector of dengue fever which is one of the most important vector-borne viral diseases worldwide ${ }^{[6,7]}$. Dengue fever can debilitate the patient for a week or more, or as the hemorrhagic form which may lead to death ${ }^{[8]}$. Anopheles stephensi is the major vector of malaria in the Indian subcontinent and some West Asian countries. Malaria remains the most serious vector-borne disease affecting about 300-500 million people and 1.4 to 2.6 million deaths annually throughout the world. More than $40 \%$ of the world's population lives in areas prone to malaria ${ }^{[9]}$. Culex quinquefasciatus is the vector of Wuchereria bancrofti and causes lymphatic filariasis and is possibly the most abundant house mosquito in towns and cities of tropical countries ${ }^{[10]}$. According to $\mathrm{WHO}{ }^{[11]}$, about 90 million people worldwide are infected with $W$. bancrofti. There are approximately 40 million people who experience severe disability due to lymphatic filariasis ${ }^{[12]}$. 
One of the approaches to combat mosquito-borne diseases relies largely on the interruption of the aquatic stages or by killing the adult mosquitoes using chemical insecticides. The drastic effects of chemical insecticides for controlling mosquitoes have received wide public apprehension ${ }^{[13]}$. To overcome these problems associated with conventional mosquito control, great efforts are required to develop innovative or complementary control techniques for mosquito species, which has resulted in the search for eco-friendly, cost-effective, and target specific insecticides against mosquito species ${ }^{[14]}$. Phytochemicals have been reported to be alternatives to synthetic pesticides and many of them are effective in mosquito control ${ }^{[15]}$. Plants or parts of plants possess a consortium of chemicals with unique biological activity ${ }^{[16]}$. Over 2000 plant species contain chemicals with pest control properties ${ }^{[17]}$, and among them, several species of plants have been shown to have some degree of activity against mosquitoes ${ }^{[18]}$.

Plant kingdom encompasses the thousands of medicinal plants, and they have been tested for their biological properties to develop medicines, pesticides, cosmetics, and food ingredients, mainly due to the presence of phytochemical constituents in these medicinal plants. Chemical compounds produced by plants known as phytochemicals are either primary metabolites, such as proteins, amino acids, common sugars, purines, and pyrimidines of nucleic acids, chlorophyll, secondary metabolites like alkaloids, flavonoids, terpenes, lignans, steroids, saponins, phenolics, and glycosides [19]. Which carry important beneficial properties like antiinflammatory, antidiabetic, antiaging, antimicrobial, antiparasitic, anticancer, antioxidant, and also mosquito larvicidal properties ${ }^{[20]}$. Piper longum L. (Pippali) is a slender, aromatic, creeping, perennial herb occurring in the hotter parts of India, from Central Himalayas to Assam and evergreen forests of the Western Ghats from Konkan to Kerala $^{[21]}$. Common usage of $P$. longumis for stomach aches, cough, tumors, and similar ailments. Piperine, piperlongumine, pipernonaline, and piperidine are the important compounds derived from P. longum [22, 24]. The various bioactive phytochemicals are characterized using Gas Chromatography-Mass Spectrometry (GC-MS), which is a very compatible technique, commonly used for the identification and quantification of the required bio-active compounds ${ }^{[25,27]}$. This study was designed to assess the larvicidal potential of the column chromatographic fraction 1 (9:1, i.e. Chloroform: Ethanol) of P. longum leaf extract on the larvae of Ae. aegypti, An. stephensi, and $C x$. quinquefasciatus. GC-MS analysis of P.longum leaf extract fraction was done to identify the major phyto compounds available in the fraction.

\section{Materials and Methods}

\subsection{Collection of $\boldsymbol{P}$. longum leaves}

Leaves were plucked from botanically authenticated $P$. longum plants, available in certain private gardens. The plucked leaves were cleaned thoroughly with tap water and dried at room temperature for 7-10 days in the shade. The dried samples were powdered using an electric blender and the sifted fine powder was transferred to airtight containers for further use.

\subsection{Extract Preparation}

$P$. longum leaf powder samples were extracted in a soxhlet apparatus using a highly polar solvent, ethanol. The extraction process was continued for about 12 hours during which time about 15 cycles of extract movement were noticed between the middle chamber and lower flask. The extraction was stopped when the solvent in the middle chamber was totally colourless. The extract was then concentrated in a Rotary Vacuum Evaporator at $40{ }^{\circ} \mathrm{C}$. Once the raw extract was totally dry, the powder was scrapped out, weighed, and placed inside a screw-capped glass bottle for further use

\subsubsection{Column Chromatographic Characterization}

About $50 \mathrm{mg}$ of the crude $P$. longum extract was dissolved in $10 \mathrm{ml}$ ethanol. The chromatographic column consisted of 60120 mesh silica gel packed inside a glass column. The compact column was initially packed and compacted using petroleum ether. The compact column was thoroughly checked for close-packing silica gel. The extract dissolved in ethanol was mixed with non-polar solvent, chloroform in 9:1 proportion. The fractions were collected separately in numbered $50 \mathrm{ml}$ beakers. The fraction was checked for the presence of active ingredients using Thin-Layer Chromatography (TLC). TLC plates were prepared using 40micron size silica gel slurry spread on glass plates and activating in a hot air oven at $110{ }^{\circ} \mathrm{C}$ for about 1 hour. The plates were cooled and about $1 \mu \mathrm{l}$ of each chromatographic fraction were loaded at the base of the plate using a micropipette. The plates were placed inside a chamber containing about $50 \mathrm{ml}$ of a solvent mixture containing 5:5 ethanol and chloroform. The chamber was closed with a glass lid and the TLC plate was taken out when the solvent reached the top portion of the plate. The movement of the solute was followed by developing the plate inside another chamber concentrated with iodine vapours.

\subsection{Phytochemical Analysis}

The presence of different phytochemical constituents with significant mosquito larvicidal activity in the chromatographic fraction was established using standard qualitative procedures $[28,30]$.

\subsection{Mosquito Rearing}

Egg cards of Ae. Aegyptiand eggs of An. Stephensi, and Cx. quinquefasciatus were procured from the Centre for Research in Medical Entomology (CRME), ICMR, Madurai. The eggs were incubated in the laboratory in three separate trays containing tap water. The larvae that hatched out were fed with powdered dog biscuits and yeast in the ratio of $3: 1$.

\subsection{Larvicidal Activity}

The larvicidal activity of $P$. longum leaf extract fraction on mosquito larvae was assessed by using the standard method prescribed by WHO ${ }^{[31]}$. The third instar Ae. aegypti, An. Stephensi, and Cx. quinquefasciatus were raised in the laboratory and removed for the experiments at the appropriate time. The larvae were exposed to the toxicants in clean $100 \mathrm{ml}$ glass beakers. The concentrations ranging from 10-80 $(\mu \mathrm{g} / \mathrm{dl})$ were tested against Ae. aegypti, An. Stephensi, and Cx. quinquefasciatus larvae. Four replicates were maintained for each concentration. The exposed larvae were continuously monitored and the mortality was recorded after $24 \mathrm{hr}$.

\subsection{GC-MS analysis}

The fraction was further characterized using Gas 
Chromatography and Mass-Spectral analysis. GC-MS analysis was carried out in South Indian Textile Research Association (SITRA), Coimbatore. Fraction dissolved in ethanol was analyzed using gas chromatography (THERMO GC- TRACE ULTRA VER: 5.0, THERMO MS DSQ-II), and the spectra pertaining to each RT values was further characterized using mass- spectral analysis. CAS library reference was used to elucidate the structure of compounds available in a particular fraction.

\subsection{Statistical Analysis}

The larval mortality data were subjected to probit analysis for calculating $\mathrm{LC}_{50}$ and $\mathrm{LC}_{90}$ values and their $95 \%$ Upper (UCL) and Lower Confidence Limits (LCL), were calculated using the dose effect probit Analysis ${ }^{[32]}$.

\section{Results}

\subsection{Screening of phytochemicals}

The preliminary phytochemical screening of $P$. longum leaf extract fraction revealed the presence of alkaloids, saponins, phytosterols, diterpenes, triterpenes, phenols, tannins, steroids, and terpenoids (Table 1).

Table 1: Phytochemical analysis of column fraction (9:1) of P.longum leaf extract

\begin{tabular}{|c|c|c|}
\hline Sl. No & Phytochemicals & Fraction 1 \\
\hline 1. & Alkaloid & + \\
\hline 2. & Glycoside & - \\
\hline 3. & Saponin & + \\
\hline 4. & Phytosterols & + \\
\hline 5. & Diterpenes & + \\
\hline 6. & Triterpenes & + \\
\hline 7. & Phenol & + \\
\hline 8. & Tannins & - \\
\hline 9. & Flavonoids & + \\
\hline 10. & Steriods & + \\
\hline 11. & Terpenoids & \\
\hline
\end{tabular}

+ Signs denotes the presence

- Signs denotes the absence

\subsection{Larvicidal efficacy}

The larvicidal activity of leaf extract fraction of $P$. longum was evaluated under laboratory condition. P. longum was an effective larvicide of the third instar larvae of Ae. aegypti, An. stephensi, and $C x$. quinquefasciatus. The larvicidal efficacy was expressed by $\mathrm{LC}_{50}$ and $\mathrm{LC}_{90}$ values at $24 \mathrm{~h}$ exposure time.
The $\mathrm{LC}_{50}$ and $\mathrm{LC}_{90}$ values against early third instar larvae of Ae. aegypti, An. stephensi, and Cx. quinquefasciatus were 38.96 and41.53; 45.06 and 71.16; 72.02 and $76.80(\mu \mathrm{g} / \mathrm{dl})$,respectively(Table 2$)$. The results indicate that the leaf extract fraction of $P$. longum possesses the potential for controlling mosquito populations.

Table 2: Probit analysis of the mortality response of third instar mosquito larvae to chromatographic fraction (9:1) of $P$. longum leaf extract after exposure for $24 \mathrm{~h}$.

\begin{tabular}{|c|c|c|c|c|c|c|}
\hline \multirow{4}{*}{$\begin{array}{l}\text { Conc. } \\
(\mu \mathrm{g} / \mathrm{dl})\end{array}$} & \multicolumn{6}{|c|}{ Mosquitoes } \\
\hline & \multicolumn{2}{|c|}{ Ae. aegypti } & \multicolumn{2}{|c|}{ An.stephensi } & \multicolumn{2}{|c|}{ Cx.quinquefasciatus } \\
\hline & $L_{50}(\mu \mathrm{g} / \mathrm{dl})$ & $L_{90}(\mu \mathrm{g} / \mathrm{dl})$ & $L_{50}(\mu \mathrm{g} / \mathrm{dl})$ & $\mathrm{LC}_{90}(\mu \mathrm{g} / \mathrm{dl})$ & $\mathrm{LC}_{50}(\mu \mathrm{g} / \mathrm{dl})$ & $\mathrm{LC}_{90}(\mu \mathrm{g} / \mathrm{dl})$ \\
\hline & LCL-UCL & LCL-UCL & LCL-UCL & LCL-UCL & LCL-UCL & LCL-UCL \\
\hline 10 & \multirow{8}{*}{$\begin{array}{c}38.96 \\
14.47-63.45\end{array}$} & \multirow{8}{*}{$\begin{array}{c}71.16 \\
46.67-95.65\end{array}$} & \multirow{8}{*}{$\begin{array}{c}41.53 \\
17.04-66.02\end{array}$} & \multirow{8}{*}{$\begin{array}{c}72.02 \\
47.53-96.51\end{array}$} & \multirow{8}{*}{$\begin{array}{c}45.06 \\
20.57-69.55\end{array}$} & \multirow{8}{*}{$\begin{array}{c}76.80 \\
52.31-101.29\end{array}$} \\
\hline 20 & & & & & & \\
\hline 30 & & & & & & \\
\hline 40 & & & & & & \\
\hline 50 & & & & & & \\
\hline 60 & & & & & & \\
\hline 70 & & & & & & \\
\hline 80 & & & & & & \\
\hline
\end{tabular}

Conc. - concentration. $\mathrm{LC}_{50}$ - lethal concentration that kills $50 \%$ of the exposed larvae, $\mathrm{LC}_{90}-$ lethal concentration that kills $90 \%$ of the exposed larvae, LCL- lower confidence limit(95\%),UCL-upper confidence limit (95\%).

\subsection{Identification of phyto compounds}

Total of twenty-nine main bio-active compounds present in the leaf extract fraction of $P$. longum were identified by using
GC-MS (Table 3 and Fig 1). The results indicate that the leaf extract fraction of $P$. longum possesses the potential for controlling mosquito populations. 
Table 3: GC-MS Characterization of P.longum leaf extract fraction (9:1)

\begin{tabular}{|c|c|c|c|}
\hline RT & Name of the compound & $\begin{array}{l}\text { Molecular } \\
\text { formula }\end{array}$ & $\begin{array}{c}\text { Molecular } \\
\text { Weight }\end{array}$ \\
\hline 3.37 & Benzene, methyl- (CAS) & $\mathrm{C} 7 \mathrm{H} 8$ & 92 \\
\hline 3.61 & Ethynylcyclopentene-(1) & C7H8 & 92 \\
\hline 5.18 & Benzene, 1, 3, 5-trimethyl- (CAS) & $\mathrm{C} 9 \mathrm{H} 12$ & 120 \\
\hline 8.20 & Dodecane, 5, 8-diethyl- (CAS) & $\mathrm{C} 16 \mathrm{H} 34$ & 226 \\
\hline 9.22 & Memantine & $\mathrm{C} 12 \mathrm{H} 21 \mathrm{~N}$ & 179 \\
\hline 10.42 & $\begin{array}{c}\text { Naphtho [1, 2-b] furan-2, 8(3H, 4H)- dione, 3a, 5, 5a, 9b-tetrahydro-3,5a,9-trimethyl- } \\
\text {,[3S-(3à, 3aà, 5aá, 9bá)]-(CAS) }\end{array}$ & $\mathrm{C} 15 \mathrm{H} 18 \mathrm{O} 3$ & 246 \\
\hline 11.31 & Tetradecane (CAS) & $\mathrm{C} 14 \mathrm{H} 30$ & 198 \\
\hline 11.31 & Tetradecane (CAS) & $\mathrm{C} 14 \mathrm{H} 30$ & 198 \\
\hline 13.76 & Allyl-5-t-butylhydroquinone & $\mathrm{C} 13 \mathrm{H} 18 \mathrm{O} 2$ & 206 \\
\hline 15.53 & Hexadecane (CAS) & $\mathrm{C} 16 \mathrm{H} 34$ & 226 \\
\hline 15.80 & Indan, 1-(2-methylpropenyl)-2-thiocyanato- & C14H15NS & 229 \\
\hline 17.35 & (5, 8-Dihydro-6-methyl-5, 8-etheno-4H-3a-azaazulen-4-y liden) acetonitrile & C14H12N2 & 208 \\
\hline 19.75 & 1-Cyano-1, 1-Dideuterio hexadecane & $\mathrm{C} 17 \mathrm{H} 31 \mathrm{D} 2 \mathrm{~N}$ & 251 \\
\hline 20.30 & 5-(Hydroxymethyl)-2-(1-methyl-2-imidazolyl)-1H-benz imidazole & $\mathrm{C} 12 \mathrm{H} 12 \mathrm{~N} 4 \mathrm{O}$ & 228 \\
\hline 21.22 & Acetic acid, 2-acetoxymethyl-4-acetylamino-4-cyano-butyl ester & $\mathrm{C} 12 \mathrm{H} 18 \mathrm{~N} 2 \mathrm{O} 5$ & 270 \\
\hline 22.28 & Pentadecanoic acid, 14-methyl-, methyl ester (CAS) & $\mathrm{C} 17 \mathrm{H} 34 \mathrm{O} 2$ & 270 \\
\hline 23.07 & 3, 7, 8-Trimethylpyrido $[2,3$-d] pyrimidine-2(3H)-, 4(8H)-dione & $\mathrm{C} 10 \mathrm{H} 11 \mathrm{~N} 3 \mathrm{O} 2$ & 205 \\
\hline 23.60 & Hexadecanoic acid, ethyl ester & $\mathrm{C} 18 \mathrm{H} 36 \mathrm{O} 2$ & 284 \\
\hline 25.62 & 10-Octadecenoic acid, methyl ester (CAS) & $\mathrm{C} 19 \mathrm{H} 36 \mathrm{O} 2$ & 296 \\
\hline 26.13 & Heptadecanoic acid, 9-methyl-, methyl ester (CAS) & $\mathrm{C} 19 \mathrm{H} 38 \mathrm{O} 2$ & 298 \\
\hline 26.93 & Docosanoic acid, 8, 9, 13-trihydroxy-, methyl ester (CAS) & $\mathrm{C} 23 \mathrm{H} 46 \mathrm{O} 5$ & 402 \\
\hline 28.93 & á-d-Mannofuranose, 2, 3:5, 6- di-O-Ethylborandiyl-1-O-(10-undecen-1-yl) - & C21H38B2O6 & 408 \\
\hline 30.55 & Heptacosane (CAS) & \begin{tabular}{|l|l} 
C27H56 \\
\end{tabular} & 380 \\
\hline 31.16 & 6"-(2-Hydroxy-3-methyl-3-butenyl)-Amentoflavone & C35H26O11 & 622 \\
\hline 31.44 & 2, 12-Dibromo-7-phenyl-5, 6, 8, 9-tetrahydrobenz[a,j]anthracene-14-carboxylate & $\mathrm{C} 33 \mathrm{H} 28 \mathrm{Br} 2 \mathrm{O} 4$ & 646 \\
\hline 31.86 & $\begin{array}{c}2,11,13,22,23,25-\text { Hexaoxa-1, } 12(1,3,2) \text {-Dibenza-24(2, 9)-1, 10-phenanthrolinabicyclo } \\
{[10.10 .3] \text { pentacosaphane }}\end{array}$ & C40H44N2O6 & 648 \\
\hline 32.17 & 1, 2-Benzenedicarboxylic acid, mono (2-ethylhexyl) ester & $\mathrm{C} 16 \mathrm{H} 22 \mathrm{O} 4$ & 278 \\
\hline 32.97 & Docosane (CAS) & $\mathrm{C} 22 \mathrm{H} 46$ & 310 \\
\hline 34.98 & \begin{tabular}{|c|} 
Heptacosane (CAS) \\
\end{tabular} & $\mathrm{C} 27 \mathrm{H} 56$ & 380 \\
\hline 35.57 & 1, 4-Dioxaspiro [4.5] decane-7-butanoic acid, 6-methyl-, 2-(methylsulfonyloxy) ethyl ester & $\mathrm{C} 16 \mathrm{H} 28 \mathrm{O} 7 \mathrm{~S}$ & 364 \\
\hline 36.60 & 7á, 9á:8à, 10à-Bis (Dimethylmethylenedioxy) 7, 8,9,10- tetrahydrobenzo [a] pyrene & $\mathrm{C} 26 \mathrm{H} 24 \mathrm{O} 4$ & 400 \\
\hline
\end{tabular}

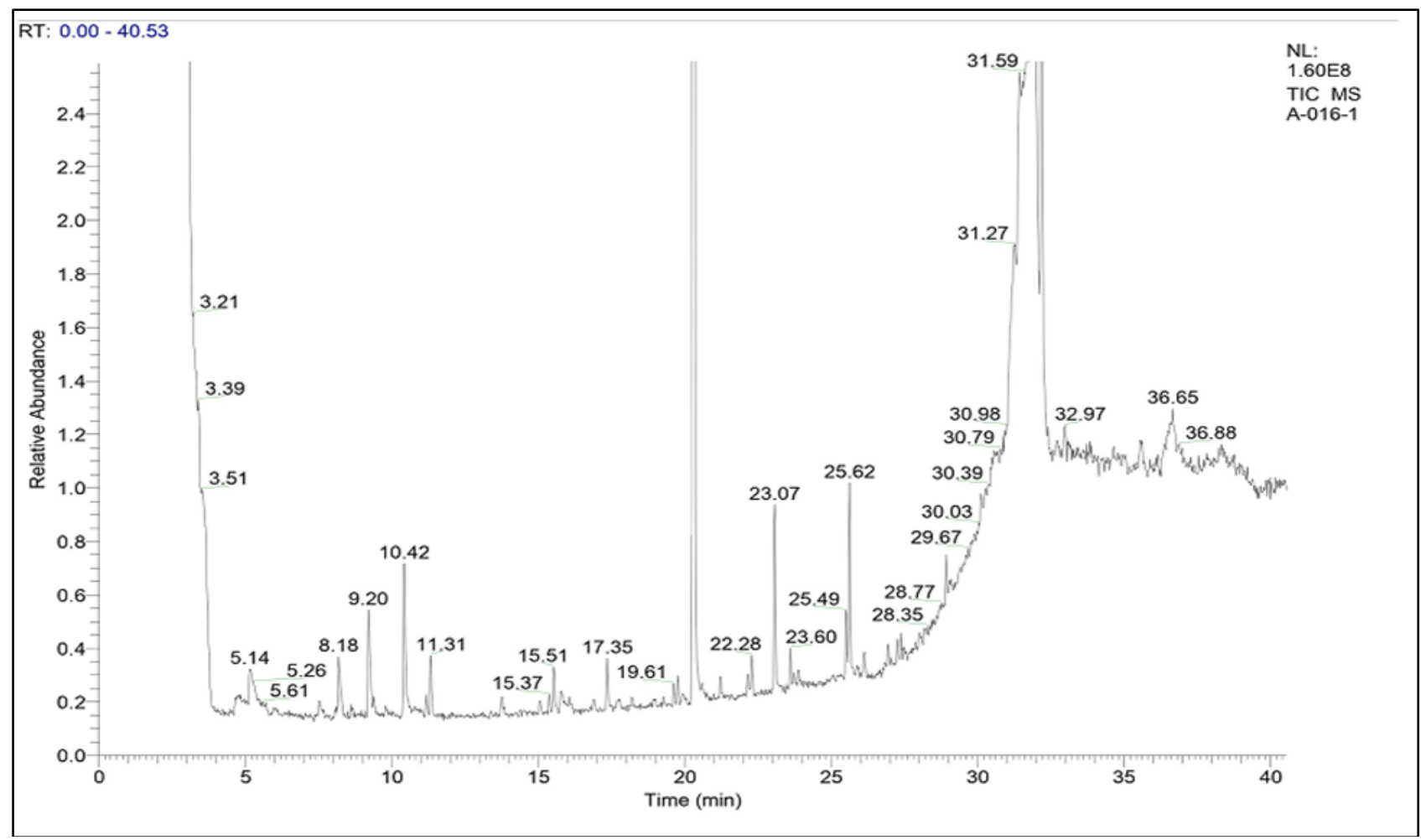

Fig 1: GC-MS Chromatogram of $P$. longum leaf extract fraction (9:1) 


\section{Discussion}

The biocidal activity of botanicals is better understood when column fractions are used. The column fractions of Acacia nilotica leaves studied by Ukwuani Kwaja et al. ${ }^{[33]}$. Phytochemical screening of A. nilotica revealed the leaves contain terpenoids, saponins, tannins, steroids, and phenols. The phytochemical analysis of column fractions of Tagetes erecta L. reported by Devika and Justin Koilpillai [34]. Mosquitoes are the most dangerous insects since they transmit several pathogens to humans. Howard et al. demonstrated the larval control can be an effective control tool due to the low mobility of larval mosquitoes, especially where the principal breeding habitats are man-made and can be easily identified [35]. Gleiser and Zygaldo discussed that the vector control program with plant extracts focused more on the elimination of mosquitoes in the larval stage. The advantage of targeting larvae is that they cannot escape from their breeding sites until the adult stage and also reduce overall pesticide use in the control of adult mosquitoes by aerial application of adulticidal chemicals ${ }^{[36]}$. Cetin et al. suggested that the plant extracts and isolated compounds would be good alternatives to control vector mosquitoes ${ }^{[37]}$. Bilal et al. reported that the plants produce many compounds naturally for defense against their pathogens and other plant-eating insects. Hence plants having different kinds of compounds and many of them possess varied levels of activity against insect pests. These plant isolated compounds could be utilized for the control of mosquitoes as they are very effective and biodegradable and not dangerous to human beings and to the environment ${ }^{[38]}$. Venkaetachalam and Jebasan identified that the phytochemicals derived from plant sources act as larvicides, insect growth regulators, repellents, and oviposition attractants and have different activities [39]. Several investigators have shown phytochemicals exhibited medicinal as well as insecticidal activities ${ }^{[40-45]}$. It was concluded from this study the presence of these phytochemicals in P. longum leaf extract fraction might be the reason for its larvicidal activity. In the present study, the $P$. longum leaf extract fraction showed enhanced larvicidal activity against all three mosquito species studied. GC-MS analysis of $P$. longum showed twenty-nine phytocompounds, among which compounds such as hexadecanoic acid andmethyl ester showed insecticidal, nematicidal, and pesticidal activities ${ }^{[46]}$. Hexadecanoic acid ethyl ester is responsible for larvicidal activity ${ }^{[47-49]}$. Thus the compounds identified in $P$. longum by GC-MS presumably led to the mortality of the larval forms of the three common mosquitoes tested.

\section{Conclusion}

The bio-active compounds in the leaves of $P$. longum show mosquito larvicidal action. It is interesting to note that the same extract exercises a killing effect on the larvae of three different species of mosquitoes. One of the fractions of $P$. longum leaf extract showed effective larvicidal properties against Ae. aegypti, An. stephensi, and Cx. quinquefasciatus. Since $P$. longum is freely available in the different tracts along the Western Ghats, there is every possibility to utilize the mosquito larvicidal compounds in the leaves of this plant in controlling the larval forms of vectors. The bio-active compounds responsible for the larvicidal action may be characterized and chemical analogues may be formulated for commercial applications

\section{Acknowledgement}

The authors acknowledge the immense help received from the Emeritus Professor S. Sam Manohar Das, Department of Zoology and Research Centre, Scott Christian College (Autonomous), for his support in conducting the study. The authors are also grateful to authors/editors/publishers of all those articles, journals, and books from where the literature for this article has been reviewed and discussed.

7. Conflict of Interest: The authors declare that there is no conflict of interest.

8. Source of Funding: No funding was received for conducting this study.

9. Ethical Approval: This study does not involve the use of animals or human subjects

\section{References}

1. WHO. A global brief on vector-borne diseases 2014.

2. Rahuman AA, Bagavan A, Kmaraj C, Saravanan E, Zahir AA, Elango G. Efficacy of the larvicidal botanical extracts against Culex quinquefasciatus Say (Dipetera: Culicidae). Journal of Parasitology Research 2009;104:1365-1372.

3. Borah R, Kalita MC, Goswami RCH, Talukdar AK. Larvicidal efficacy of crude seed extract of six important oil yielding plants of north east India against the mosquitoes Aedes aegypti and Culex quiquefasciatus. Journal of Biofertilizers and Biopesticides 2010;3(2):2-4.

4. Latha C, Vijayakumar PD, Velayutham S, Joshep A. Biological activity of Indigenous plant extracts as mosquito larvicides. Indian Journal of Experimental Biology 1999;37:206-208.

5. Jaswanth A, Ramanathan P, Ruckmani K. Evaluvation of Mosquito activity of Annona Squamosa leaves against filarial vector mosquito, Culex quinquefasciatus. Indian Journal of Experimental Biology. 2001;40:363-365.

6. Orsi FA, Angeraami RN, Mazetto BM, Quaino SKP, Santiago-Bassora F, Castro V, et al. Reduced thrombin formation and excessive fibrinolysis are associated with bleeding complications in patients with dengue fever: A case-control study comparing dengue fever patients with and without bleeding manifestations. BMC Infectious Diseases 2013;13:2-10.

7. Vasanwala FF, Thein TT, Leo YS, Gan VC, Hao Y, Lee LK. Predictive value of proteinuria in adult dengue severity. PLOS Neglected Tropical Diseases 2014;8:1-6.

8. Neves-Filho RAW, Silva CA, Silva CSB, Navarro DMAF, Santos FAB. Improved microwave-mediated synthesis of 3-(3-aryl-1, 2, 4-oxadiazol-5-yl) propionic acids and their larvicidal and fungal growth inhibitory properties. Chemical and Pharmaceutical Bulletin 2009;57:819-825.

9. Hemalatha P, Elumalai D, Janaki A, Babu M, Velu K, Velayutham K, et al. Larvicidal activity of Lantana camaraaculeat aagainst three important mosquito species. Journal of Entomology and. Zoology Studies 2015;3(1):174-181.

10. Reegan AD, Rajiv Gandhi M, Paulraj MG, Ignacimuthu S. Ovicidal and Oviposition Deterrent Activities of Medicinal Plant Extracts against Aedes aegypti L. and Culex quinquefasciatus Say Mosquitoes (Diptera: 
Culicidae). Osong Public Health and Research Perspectives 2015;6(1):64-69.

11. WHO. World malaria report, Geneva 2013, WHO/HTM/MAL/2013:1102 .

12. Addiss DG. Global elimination of lymphatic filariasis. A 'Mass uprising of compassion" Plos Neglected. Tropical Diseases 2013;7(8):2264.

13. ICMR Bulletin. Chemical insecticides in malaria vector in India 2002;32:10.

14. McGraw EA, ONeill SL. Beyond insecticides: new thinking on an ancient problem. Nature Reviews Microbiology 2013;11(3):181-93.

15. Sukumar K, Perich MJ, Boobar LR. Botanical derivativesin mosquito control a review. Journal of the American Mosquito Control. Association 1991;7:210237.

16. Fransworth NR, Bingel AS. Problems and prospects of discovering new drugs from higher plants by pharmacological, Biological or Therapeutical Activity $\mathrm{H}$. Wagner and P. Wolff, eds. Springer-Verlag, New York 1977.

17. Ahmad MZ, Akhter S, Jain GK, Rahman M, Pathan SA, Ahmad FJ, et al. Metallic nanoparticles: Technology overview and drugdelivery applications in oncology. Expert Opinion on Drug Delivary 2010;7(8):927-42.

18. Kumar A, Dutta GP. Indigenous plant oils as larvicidal agent against Anopheles Stephensi mosquitoes. Current. Science 1987;56:959-960.

19. Ramawat KG, Dass S, Mathur M. The Chemical Diversity of Bioactive Molecules and Therapeutic Potential of Medicinal Plants. In: Herbal Drugs: Ethno medicine to Modern Medicine. New York, Springer 2009, 7-32.

20. Bahramsoltani R, Farzaei MH, Rahimi R. Medicinal plants and their natural components as future drugs for the treatment of burn wounds: an integrative review. Archives of Dermatological Research 2014;306(7):60117.

21. Satyavati GV, Gupta AK, Tandon N. Medicinal plants of India. Indian Council of Medical Research. New Delhi 1987;2(25):42.

22. Kiritikar KR, Basu BD. Indian medicinal plants. 2nd edn, Dehradun, International book distribution III, 1987, 1664-1666.

23. Reddy PS, Jamil PK, Madhusudhan, Anjani G, Das B. Antibacterial activity of isolates from Piper. longum and Taaxus baccata. Pharmaceutical. Biology 2001;39(3):236-238.

24. Prasad MP, Shekhar S, Amit B. Phytochemical Analysis and Antioxidant potential of Piper Species and its Molecular characterization by RAPD Markers. International Journal of Fundamental Applied Sciences 2012;1(4):71-73.

25. Robertson DG. Metabonomics in toxicology: A review. Toxicological Sciences 2005;85(2):809-822.

26. Fernie AR, Trethewey RN, Krotzky AJ, Willmitzer L. Metabolite profiling: From diagnostics to system biology. Nature Reviews Molecular Cell Biology 2004;5(9):763765.

27. Kell DB, Brown M, Davey HM, Dunn WB, Spasic I, Oliver SG. Metabolic foot printing diagnostics to Systems biology. The medium is the message. Nature Reviews Molecular Cell Biology 2005;3(7):557-65.
28. Trease GM, Evans WC. Pharmacognosy. 11th edn. BailliereTindall: London 1989, 45-50.

29. Sofowra A. Medicinal Plants and traditional medicine in Africa. Spectrum Books Ltd. Ibadan: Nigeria 1993, 91289.

30. Harborne JB. Phytochemical Methods. London: Chapman and Hall Publications 1998, 7-8.

31. World Health Organization. Guidelines for laboratory and field testing of mosquito larvicides. Geneva 2005.

32. Finney DJ. In: Probit Analysis. London, Cambridge University Press 1971, 68-72.

33. Ukwuani-Kwaja AN, Dabai YU, Samuel R, Odoh JO. Antibacterial activity of column fractions of Acacia Nilotic leaves extract. Pharmaceutical Chemistry Journal 2016;3(3):38-42.

34. Sasidharan S, Chen Y, Saravanan D, Sundaram KM, Latha LY. Extraction, isolation and characterization of bioactive compounds from plant extracts. African Journal of Traditional, Complementary Alternative Medicines 2011;8(1):1-10.

35. Devika R, Koilpillai J. Column chromatographic separation of bioactive compounds from Tagetes erecta. International Journal of Pharmaceutical Sciences and Research 2015;6(2):762-766.

36. Howard AF, Zhou G, Omlin FX. Malaria mosquito control using edible fish in western Kenya: preliminary findings of a controlled study. BMC Public Health 2007;7:199.

37. Gleiser RM, Zygadlo JA. Insecticidal properties of essential oils from Lippia turbinata and Lippia polystachya (Verbenaceae) against Culex quinquefasciatus (Diptera: Culicidae). Parasitology Research 2007;101:1349-1354.

38. Cetin H, Yanikoglu A, Cilek JE. Larvicidal activity of selected plant hydrodistillate extracts against the house mosquito, Culex pipiens, a West Nile virus vector. Parasitology Research 2011; 108(4):943-948.

39. Bilal A, Jahan N, Ahmed A, Bilal SN, Habib S, Hjra S. Phytochemical and pharmacological studies on Ocimum basilicum L. - a review. International Journal of Current Research and Review 2012;4(23):73-83.

40. Shaalan EAS, Canyonb D, Younes MWF, Wahab HA, Mansour AH. A review of botanical phytochemical with mosquitocidal potential. Environment International 2005;3:1149-1166.

41. Kim SI, Ahn YJ. Larvicidal activity of lignans and alkaloid identified in Zanthoxylum Piperitum bark toward insecticide-susceptible and wild Culex pipiens pallens and Aedes. aegypti. Parasites and Vectors 2017;10(1):221-230.

42. Rahuman A, Bagavan A, Kamaraj C, Vadivelu M. Evaluation of indigenous plant extracts against larvae of Culex quinquefasciatus Say (Diptera: Culicidae). Parasitology Research 2008;104(3):637-643.

43. Morrissey JP, Osbourn AE. Fungal resistance to plant anti-biotics as a mechanism of pathogenesis. Microbiology and Molecular Biology Reviews 1999;63(3):708-24.

44. Chapagain BP, Wiesman Z. Larvicidal Activity of the Fruit Mesocarp Extract of Balanites aegyptiaca and its Saponin fractions against Aedes egypti. Dengue Bulletin 2005;29:203-207. 
45. Pelah D, Abramovich Z, Markus A, Wiesman Z. The use of commercial saponin from Quillajas aponaria bark as a natural larvicidal agent against Aedes aegypti and Culex pipiens. Journal of Ethnopharmacology 2002;81:407-409.

46. Kannathasan K, Senthilkumar A, Venkatesalu V, Chandrasekaran M. Larvicidal activity of fatty acid methyl esters of Vitex species against Culex quinquefasciatus. Parasitology Research 2008;103:9991001.

47. Ghayal N, Toro V, Biware M, Padhye A. Larvicidal effects of GC-MS fractions from leaf extracts of Cassia uniflora Mill nonspring International Journal of Pharmaceutical Sciences Review and Research 2020;63(1):149-155.

48. Tyagi T, Agarwal M. Phytochemical screening and GCMS analysis of bioactive constituents in the ethanolic extract of Pistia stratiotes L. and Eichhornia crassipes (Mart.) solms. Journal of Pharmacognosy and Phytochemistry 2017;6(1):195-206.

49. Jegadeeswari $\mathrm{P}$, Nishanthini A, Muthukumarasamy S, Mohan V. GC-MS analysis of bioactive components of Aristolochia krysagathra (Aristolochiaceae). Journal of Current Chemical and Pharmaceutical Sciences 2012;2(4):226-232. 